\title{
Solid self-nanoemulsifying cyclosporin A pellets prepared by fluid-bed coating: preparation, characterization and in vitro redispersibility
}

This article was published in the following Dove Press journal:

International Journal of Nanomedicine

16 April 2011

Number of times this article has been viewed

\section{Yang Lei ${ }^{1,2}$ \\ Yi Lu \\ Jianping $\mathrm{Qi}^{2}$ \\ Sufang $\mathrm{Nie}^{1}$ \\ Fuqiang $\mathrm{Hu}^{3}$ \\ Weisan Pan' \\ Wei Wu ${ }^{2}$}

'School of Pharmacy, Shenyang Pharmaceutical University, Shenyang;

${ }^{2}$ School of Pharmacy, Fudan University, Shanghai; ${ }^{3}$ School of Pharmacy,

Zhejiang University, Hangzhou,

Zhejiang, People's Republic of China

Correspondence: Wei Wu School of Pharmacy, Fudan University, 826 Zhangheng Road, Shanghai 20I203, People's Republic of China

Tel +862151980002

Fax +862151980002

Email wuwei@shmu.edu.cn
Background: The objective of this study was to evaluate fluid-bed coating as a new technique to prepare a pellet-based solid self-nanoemulsifying drug delivery system (SNEDDS) using cyclosporin A as a model of a poorly water-soluble drug.

Methods: The rationale of this technique was to entrap a Liquid SNEDDS in the matrix of the coating material, polyvinylpyrrolidone K30, by fluid-bed coating. Pseudoternary phase diagrams were used to screen the liquid SNEDDS formulations. The optimal formulation was composed of Labrafil $\mathrm{M}^{\circledR} 1944$ CS, Transcutol $\mathrm{P}^{\circledR}$, and Cremophor ${ }^{\circledR}$ EL in a ratio of 9:14:7. To prepare solid SNEDDS pellets, liquid SNEDDS was first dispersed in an aqueous solution of polyvinylpyrrolidone and then sprayed onto the surface of non-pareil pellets. Upon evaporation of water, polyvinylpyrrolidone precipitated and formed tight films to entrap the liquid SNEDDS. Visual observation and scanning electron microscopic analysis confirmed good appearance of the solid SNEDDS pellets.

Results: Our results indicated that up to $40 \%$ of the liquid SNEDDS could be entrapped in the coating layer. Powder x-ray diffraction analysis confirmed nonexistence of crystalline cyclosporin A in the formulation. Solid SNEDDS pellets showed a slower redispersion rate than the liquid SNEDDS. An increase in the total liquid SNEDDS loading led to faster redispersion, whereas increased coating weight (up to $400 \%$ ) significantly decreased the redispersion rate. Both cyclosporin A loading and protective coating with 5\% polyvinylpyrrolidone K30 did not significantly affect the redispersion rate.

Conclusion: It is concluded that fluid-bed coating is a new technique with considerable potential for preparation of pellet-based solid SNEDDS formulations.

Keywords: solid, self-nanoemulsifying, fluid-bed coating, cyclosporin A, pellets

\section{Introduction}

A large number of marketed drugs or drug candidates are poorly water-soluble, which results in poor oral absorption, high intrasubject and intersubject variability, and lack of dose proportionality. ${ }^{1}$ In order to overcome these problems, different approaches, including solid dispersion, inclusion complexation, cosolubilization, and micronization, have been employed. ${ }^{2}$ Recently, much attention has been paid to lipid-based formulations, especially self-emulsifying and self-nanoemulsifying drug delivery systems (SNEDDSs). ${ }^{3}$ In general, SNEDDS is an isotropic mixture of drug, oil, surfactants, and cosurfactants, which forms an oil-in-water nanoemulsion upon contact with aqueous medium under gentle agitation. ${ }^{4-6}$ SNEDDSs are commonly formulated in a liquid state and further encapsulated into soft gelatin capsules before use. However, the soft capsule formulations have some disadvantages, including low drug compatibility, poor 
stability, drug leakage and precipitation, capsule aging, and high production costs. Therefore, it is desirable to formulate SNEDDSs into solid dosage forms.

One of the initial concepts of a solid SNEDDS was proposed by Nazzal et al when they were formulating a eutectic liquid ${ }^{7,8}$ into a tablet using blends of maltodextrin, modified povidone, and microcrystalline cellulose, ${ }^{9,10}$ which was termed "liquisolid" or solid-lipid compact. From then on, a number of techniques have been employed to prepare solid SNEDDSs. A common strategy is to formulate a liquid SNEDDS into granules using porous adsorbents and subsequently compress these into tablets. ${ }^{11-15}$ Spray-drying has also been employed to formulate liquid SNEDDSs into free-flowing powders, using adsorbents such as Aerosil $200^{16}$ and dextran. ${ }^{17}$ Homar et $\mathrm{al}^{18}$ and Zvonar et $\mathrm{al}^{6}$ reported microencapsulation of liquid SNEDDSs to obtain solid powders of microcapsules. The powders containing liquid SNEDDS can be further formulated into solid dosage forms, such as tablets, capsules, and granules. In recent years, there has been growing interest in multiple-unit pellet formulations, which have appealing properties, including independence of gastric transit, flexibility in dose dividing, reduction of intrasubject and intersubject variability, and improvement in efficacy and safety. SNEDDS pellets have been developed and evaluated both in vitro and in vivo in order to enhance the solubility and bioavailability of poorly water-soluble drugs. ${ }^{19-23}$ Up until now, melt extrusion/spheronization has been employed as the only technique to prepare SNEDDS pellets. The formulation process depends highly on liquid SNEDDSs as moistening agents or adhesives to prepare paste for extrusion, which makes formulation development less flexible.

In our previous studies, ${ }^{24-26}$ we developed a fluid-bed coating technique to prepare solid dosage forms, such as solid dispersion and cyclodextrin inclusion complexes, from liquids. This technique is based on removal of the solvent from the bulk liquid, while the solid precipitates and deposits on the surface of non-pareil cores simultaneously. The coating process is highly efficient and can be easily scaled up. In this study, we employed this fluid-bed coating technique to prepare a solid SNEDDS. To avoid use of an organic solvent, the liquid SNEDDS was directly dispersed in water and spray-dried to achieve coating, using polyvinylpyrrolidone $\mathrm{K} 30$ as a film-forming material in a fluid-bed coater. The most important issues with this technique, including the capacity of the coating layer to "hold" a liquid SNEDDS, and the redispersibility and physicochemical properties of solid SNEDDS pellets, were investigated.

\section{Materials and methods}

\section{Materials}

Cyclosporin A was purchased from the Pharmaceutical Factory at the Sichuan Institute of Antibiotic Industries (Chengdu, China). Oleoyl macrogolglycerides (Labrafil $\mathrm{M}^{\circledR}$ 1944 CS), caprylocaproyl macrogolglycerides $\left(\right.$ Labrasol $^{\circledR}$ ), and diethylene glycol monoethyl ether (Transcutol $\mathrm{P}^{\circledR}$ ) were purchased from Gattefossé Corporation (Brittany, France). Ethoxylated castor oil (Cremophor ${ }^{\circledR}$ EL) and polyethylene glycol (PEG)-40 hydrogenated castor oil (Cremophor RH 40) were obtained from BASF Corporation (Ludwigshafen, Germany). PEG 400 was purchased from Gaonan Chemicals (Shanghai, China). Polyvinylpyrrolidone K30 was kindly provided by the China Division, ISP Chemicals Co (Shanghai, China). Non-pareil pellets (Suglets ${ }^{\circledR}$ sugar spheres PF101, 710-850 $\mu \mathrm{m}$ in diameter) were provided by NP Pharm (Bazainville, France). High-pressure liquid chromatographic grade methanol, acetonitrile, and tert-butylmethylether were provided by Tedia (Carson City, CA). Deionized water was prepared using the Millipore purification system (Molsheim, France). Other reagents were of analytical grade and used as received.

\section{Preparation and characterization of liquid SNEDDS}

The formulation of the liquid SNEDDS was first screened and evaluated before the preparation of the solid SNEDDS. Liquid SNEDDS should have the capacity to solubilize sufficient drug to avoid possible precipitation during the self-nanoemulsifying process. To begin with, the solubility of cyclosporin A in oils, surfactants, and cosurfactants was investigated. Briefly, excess cyclosporin A was added to each of the liquids, after which the mixture was maintained at $25^{\circ} \mathrm{C}$ for 24 hours to reach equilibrium following a previously described procedure. ${ }^{27}$ After centrifugation, the supernatant was collected and assayed for cyclosporin A by high-pressure liquid chromatography as described below. The highest apparent solubility of cyclosporin A was observed in the following order: 1,2-propylene glycol (430 mg/g), Transcutol P (340 mg/g), ethyl oleate (125 mg/g), and Labrafil M 1944 CS (123 mg/g). However, the solubility of cyclosporin A in surfactants (such as Cremophor RH 40 and Cremophor EL) was moderate (about $80 \mathrm{mg} / \mathrm{g}$ ).

Liquid SNEDDS formulations were screened by pseudoternary phase diagrams using Labrafil M 1944 CS and ethyl oleate as oils, Cremophor EL and RH40 as surfactants, and Transcutol P and 1,2-propylene glycol as cosurfactants, 
due to the relatively high solubility of cyclosporin A in these excipients and their good pharmaceutical acceptance. During the construction of the ternary phase diagrams, the composition of oil, surfactant/cosurfactant, and water was fixed as the three vertices of the triangle phase diagram. ${ }^{27}$ Mixtures of oil and surfactant/cosurfactant were titrated by deionized water at $37^{\circ} \mathrm{C}$. The mixtures were vortex-mixed, and then observed visually to identify the formation of nanoemulsion presenting as clear or translucent liquids. From the region of self-nanoemulsifying (infinite dilution region within the nanoemulsion region) in the phase diagram, the ratio of oil to surfactant/cosurfactant could be easily obtained. By comparing a series of phase diagrams at different surfactant/cosurfactant ratios $\left(\mathrm{K}_{\mathrm{m}}\right)$, the composition of liquid SNEDDS could be roughly selected. Cyclosporin A was dissolved in blank liquid SNEDDS, and its self-nanoemulsifying ability was evaluated by visual observation and particle size measurement.

The optimal formulation of cyclosporin A-loaded liquid SNEDDS was simply prepared by mixing the components selected above. Due to the poor solubility of cyclosporin A, it was first dissolved in cosurfactant liquid. Oils and surfactants were then added, and the solution was gently stirred to form a homogenous mixture.

\section{Preparation and characterization of solid SNEDDS pellets}

\section{Preparation}

Solid SNEDDS pellets were prepared in a fluid-bed coater (DPL1/3 Multi-processor, Chongqing Jinggong Pharmaceutical Machinery Co Ltd, Chongqing, China) according to previously described procedures with modifications. ${ }^{24,25}$ Briefly, $500 \mathrm{~mL}$ of liquid SNEDDS was diluted with $500 \mathrm{~mL}$ of water under gentle stirring. Subsequently, a defined amount of diluted liquid SNEDDS was poured into an aqueous solution containing polyvinylpyrrolidone K30 under mechanical stirring to achieve a final mixture containing $10 \%$ polyvinylpyrrolidone $\mathrm{K} 30(\mathrm{w} / \mathrm{v})$ and liquid SNEDDS at a series of concentrations less than $10 \%(\mathrm{w} / \mathrm{v})$. The mixture was then sprayed through a nozzle onto the surface of fluidized non-pareil cores in the fluid-bed coater. Operating conditions were as follows: inlet air temperature, $45-55^{\circ} \mathrm{C}$; product temperature, $35^{\circ} \mathrm{C}$; blower frequency, $12-26 \mathrm{~Hz}$; rotational speed of peristaltic pump, 4-12 rpm; atomizing air pressure, $0.15-0.25 \mathrm{mPa}$; and spray nozzle diameter, $0.5 \mathrm{~mm}$. After coating, the pellets were dried in the coating chamber at $35^{\circ} \mathrm{C}$ for an additional 15 minutes. For the protective coating, the solid SNEDDS pellets were further coated with polyvinylpyrrolidone K30, with a 5\% weight gain.

\section{Coating recovery and coating weight gain}

The coating recovery $(C R)$ was defined as the ratio of the weight of the final solid SNEDDS pellet product $\left(W_{\mathrm{F}}\right)$ to the total weight of non-pareil cores, polyvinylpyrrolidone $\mathrm{K} 30$, and liquid SNEDDS $\left(W_{\mathrm{T}}\right)$, and was calculated as: $C R(\%)=W_{\mathrm{F}} / W_{\mathrm{T}} \times 100 \%$.

The coating weight gain $(C W G)$ was used to define the ratio of the increased weight of solid SNEDDS layer compared with the weight of non-pareil cores $\left(W_{\mathrm{C}}\right)$, and was calculated as: $C W G(\%)=\left(W_{\mathrm{F}}-W_{\mathrm{C}}\right) / W_{\mathrm{C}} \times 100 \%$, where $W_{\mathrm{C}}$ denotes the weight of the original non-pareil cores.

\section{Friability}

Friability of the solid SNEDDS pellets was measured by the Chinese Pharmacopoeia Appendix method. The pellets were weighed and subjected to friability testing in a CJY-300B tester (Shanghai Huanghai Pharmaceutical Control Equipment Co Ltd, Shanghai, China) at $25 \mathrm{rpm}$ for 4 minutes. The friability was calculated as the percentage of weight loss. A limit of $1 \%$ for friability tests was suggested by the Chinese Pharmacopoeia 2010 edition.

\section{Scanning electron microscopy}

Both the surface and cross-section morphology of the solid SNEDDS pellets were observed by a scanning electron microscope (XL30 Series; Philips, Amsterdam, Holland). Prior to examination, the samples were fixed on a brass stub using double-sided tape and gold-coated in vacuum by a sputter coater. The photographs were taken at an excitation voltage of $10 \mathrm{kV}$.

\section{Powder x-ray diffraction}

Powder X-ray diffraction of the samples (cyclosporin A, polyvinylpyrrolidone K30, physical mixture, and solid SNEDDS powder) was evaluated by an $\mathrm{X}^{\prime}$ Pert PRO diffractometer (PANalytical, Almelo, Holland) over the $2.5-45^{\circ} 2 \theta$ range at a scan rate of $3^{\circ}$ per minute, where the tube anode was $\mathrm{Cu}$ with $\mathrm{Ka}=0.154 \mathrm{~nm}$ monochromatized with a graphite crystal. The pattern was collected at $40 \mathrm{kV}$ of tube voltage and $60 \mathrm{~mA}$ of tube current in step scan mode (step size $0.02^{\circ}$, counting time 1 second per step). In order to exclude interference of the non-pareil cores with the x-ray diffraction analysis, the solid SNEDDS samples were prepared with inert polyvinylchloride beads as a substrate and crushed to collect the powder. To prepare the physical mixtures, blank solid SNEDDS powder containing 40\% liquid SNEDDS was mixed with cyclosporin A powder to simulate one of the solid SNEDDS formulations that contained $40 \%$ liquid 
SNEDDS in the coating layer and $10 \%$ cyclosporin A in liquid SNEDDS.

\section{Particle size and zeta potential measurement}

The particle size and zeta potential of the nanoemulsion was measured by Zetasizer $\mathrm{Nano}^{\circledR}$ (Malvern Instruments, Malvern, UK) equipped with a $4 \mathrm{~mW}$ He-Ne laser (633 nm) at $25^{\circ} \mathrm{C}$. Samples were diluted with ten volumes of deionized water prior to the measurement.

\section{Reconstitution study}

The solid SNEDDS pellets $(100 \mathrm{mg}$ ) were dispersed with $10 \mathrm{~mL}$ deionized water by vortex mixing (30 seconds), and then incubated for 30 minutes at $25^{\circ} \mathrm{C}$. The dispersion was then observed visually and characterized for particle size.

\section{Redispersibility study}

The solid SNEDDS pellets should preserve their ability to reconstitute into nanoemulsion upon contact with water. In this study, the redispersibility of solid SNEDDS pellets was evaluated by monitoring cyclosporin $\mathrm{A}$ in the redispersing medium. Previously, similar "dissolution" studies have been performed to characterize SNEDDSs. ${ }^{4,28}$ However, it would be better to use the term "redispersibility study" rather than "dissolution study" because those evaluations were based on the quantification of total cyclosporin A in reconstituted nanoemulsion rather than free cyclosporin $\mathrm{A}$. The redispersibility test was performed in a ZRS-8G dissolution tester (Tianda Tianfa Technology Co Ltd, Tianjin, China) according to the Chinese Pharmacopoeia Appendix Method I (the basket method) with minor modifications. The redispersing medium was $500 \mathrm{~mL}$ of deionized water thermostatically maintained at $37 \pm 0.5^{\circ} \mathrm{C}$ and stirred at a revolution speed of $100 \mathrm{rpm}$. Solid SNEDDS pellets containing $25 \mathrm{mg}$ cyclosporin A were first sealed into hard gelatin capsules and immersed into $500 \mathrm{~mL}$ redispersing medium. Five milliliter aliquot samples were withdrawn at time intervals and immediately filtered (Millex ${ }^{\circledR}$ AP, Millipore, $\left.0.4 \mu \mathrm{m}\right)$. The filtrate $(500 \mu \mathrm{L})$ was diluted with $500 \mu \mathrm{L}$ methanol, and a $20 \mu \mathrm{L}$ sample was assayed for cyclosporin A by high-pressure liquid chromatography as described below.

\section{Determination of cyclosporin A}

Cyclosporin A was determined by high-pressure liquid chromatography/ultraviolet light at a detection wavelength of $226 \mathrm{~nm} .{ }^{29}$ The LC-10ATvp high-pressure liquid chromatography system (Shimadzu, Kyoto, Japan) was composed of a binary pump, a tunable ultraviolet detector, a column heater, and a manual injector. The mobile phase was a mixture of acetonitrile/water/tert-butylmethylether/ phosphoric acid (610/340/50/1, v/v/v/v) pumped at a flow rate of $1.0 \mathrm{~mL} /$ minute. Cyclosporin A was separated by a C18 column (Venusil XBP, $5 \mu \mathrm{m}, 4.6 \mathrm{~mm} \times 150 \mathrm{~mm}$; Agela, Newark, DE), which was guarded with a refillable precolumn $(\mathrm{C} 18,2.0 \mathrm{~mm} \times 20 \mathrm{~mm}$; Alltech, Nicholasville, $\mathrm{KY}$ ) and a stainless preheating tube with a length of $1000 \mathrm{~mm}$ and an internal diameter of $0.25 \mathrm{~mm}$. The temperature of the $\mathrm{C} 18$ column and the preheating tube was maintained at $70^{\circ} \mathrm{C}$. Samples were prepared according to the following procedures: for liquid SNEDDS, the samples were directly diluted with methanol; for solid SNEDDS, the pellets were first ground into fine powder and extracted with methanol; and for the redispersibility study, the samples were directly diluted with methanol to destroy the nanoemulsion structure and release cyclosporin A. The linearity ranged from 1.0 to $50 \mu \mathrm{g} / \mathrm{mL}$, with a correlation coefficient of $0.9997 \pm 0.0002$. Intraday and interday precisions were all below $2 \%$.

\section{Statistical analysis}

All results were expressed as the mean \pm standard deviation. Data for the different formulations were compared by one-way analysis of variance. $P<0.05$ was considered to be statistically significant.

\section{Results and discussion}

\section{Preparation and characterization of liquid SNEDDS}

The results of the phase diagram study outline the range of oil, surfactant, and cosurfactant combinations that possess a good self-nanoemulsifying ability, as shown in a typical pseudoternary phase diagram (Figure 1). In the phase diagram, the area of self-nanoemulsifying, which can be diluted infinitely without obvious changes in appearance, is shown in dark, whereas the nanoemulsion area, which transits into a milky emulsion upon dilution with water, is shown in gray. From the self-nanoemulsifying areas, the ratio of oil/(surfactant + cosurfactant) could be easily read. By carefully comparing the phase diagrams obtained at different $\mathrm{K}_{\mathrm{m}}$ (surfactant/cosurfactant) values, we estimated the self-nanoemulsifying formulation range. The optimal formulation was selected according to the criteria of rapid self-nanoemulsifying ability, higher solubility of cyclosporin A, and less use of surfactants. Table 1 shows six optimal formulations containing different types of oils, surfactants, and cosurfactants, which were further evaluated for their ability to solubilize cyclosporin A. We found that the highest solubility 

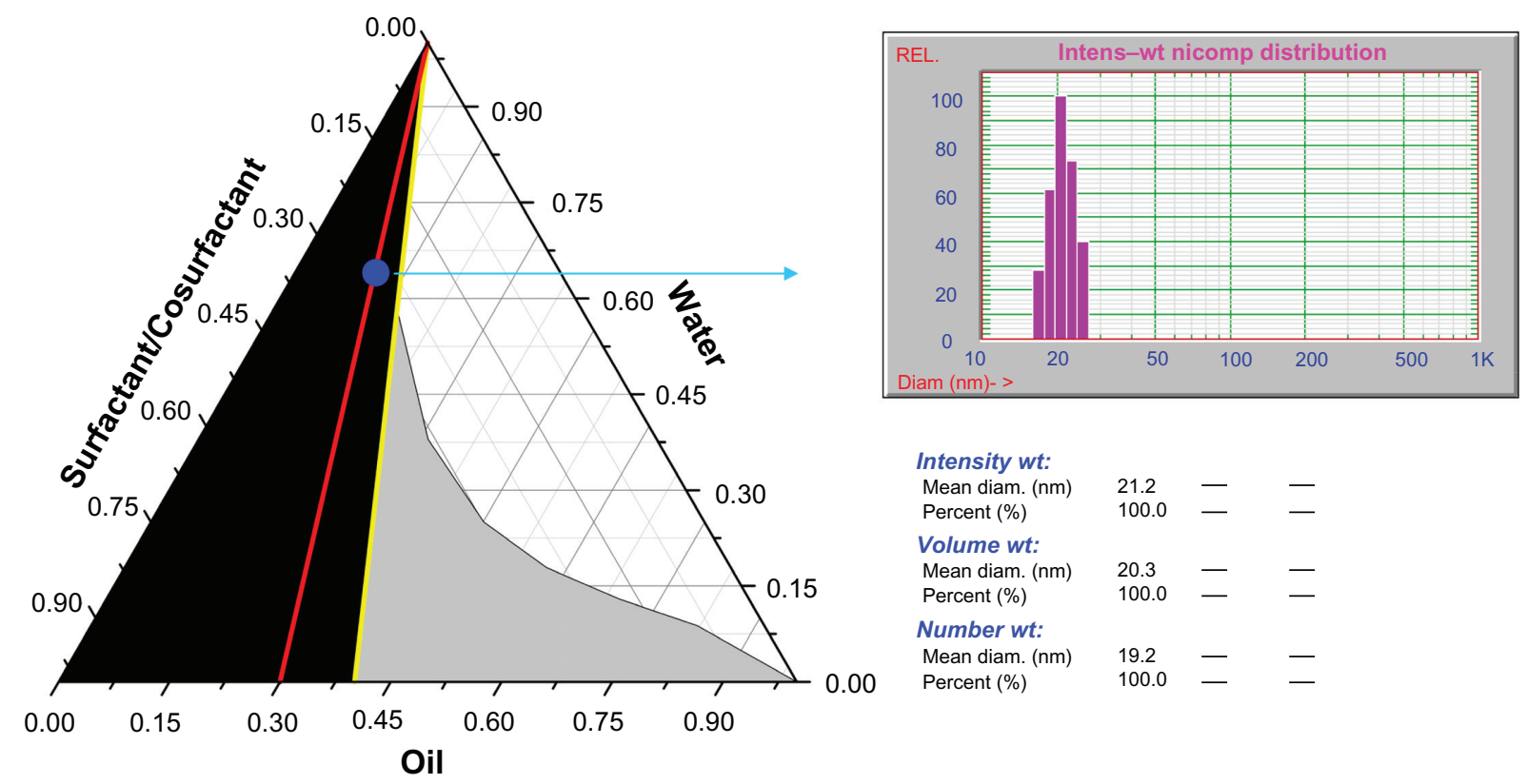

Figure I A typical pseudoternary phase diagram with deionized water, Labrafil $\mathrm{M}^{\circledR}$ I944 CS (oil) and Cremophor ${ }^{\circledR}$ EL/Transcutol $\mathrm{P}^{\circledR}$ (surfactant/cosurfactant, $\mathrm{K}_{\mathrm{m}}=2$ ) as three vertices. The dark region indicates area of self-nanoemulsifying (infinite dilution), whereas the gray region indicates an area of nanoemulsion that turns into a milky emulsion upon dilution with water. The red line shows the dilution profile of the liquid SNEDDS (F4 in Table I) for the solid SNEDDS pellets study. The blue point indicates the nanoemulsion dispersion of the liquid SNEDDS after dilution with water. The particle size was $21.2 \mathrm{~nm}$ as measured by Zetasizer Nano.

Abbreviation: SNEDDS, self-nanoemulsifying drug delivery system.

of $170 \mathrm{mg} / \mathrm{g}$ and $160 \mathrm{mg} / \mathrm{g}$ was from formulation 4 (F4) and formulation 6 (F6), respectively (Table 1). Figure 1 shows that the particle size of $\mathrm{F} 4$ was approximately $21 \mathrm{~nm}$, which was determined after ten times of dilution by water. Furthermore, up to $10 \%$ of cyclosporin A loading did not significantly affect particle size (Table 1). However, the particle size was significantly increased by up to $12 \%$ cyclosporin A loading. Being highly hydrophobic, increase of cyclosporin A content up to such a high level seemed to result in significant alteration in the phase behavior of the system, which led to an increase in the particle size after self-nanoemulsifying. For F6, we observed much bigger particle size at all drug loading levels. This is due to the different phase behavior of other formulations that have different compositions.

Based on these findings, we selected F4 with an oil:surfactant:cosurfactant ratio of 9:14:7 for further study of solid SNEDDS pellets. Each $1000 \mathrm{mg}$ blank liquid SNEDDS contained 300 mg Labrafil M 1944 CS, 466.7 mg Cremophor EL, and $233.3 \mathrm{mg}$ Transcutol P. This formulation was clear and able to self-nanoemulsify into a translucent nanoemulsion dispersion upon addition of water under gentle shaking. The particle size and zeta potential of the nanoemulsion dispersion was $21.2 \pm 2.6 \mathrm{~nm}$ and $-12.60 \mathrm{mV}$, respectively. The nanoemulsion dispersion showed no obvious changes in appearance after storage at ambient atmosphere for 1 week.

\section{Preparation and characterization of solid SNEDDS pellets}

Because this was a new attempt to prepare solid SNEDDS by fluid-bed coating, several important issues concerning this technique should be clarified first, including the coating procedures and coating formulations.

In order to avoid use of an organic solvent, we used an aqueous dispersion of SNEDDS for coating. As observed in the liquid SNEDDS formulation, the aqueous dispersion of SNEDDS was in fact a dispersion of nanoemulsion. We hypothesized that the nanoemulsion dispersion could be reconcentrated and entrapped in the matrix of the coating layer after removal of water during the fluid-bed coating process. To entrap the liquid SNEDDS in the coating layer efficiently, it is very important to choose the appropriate coating materials. The coating materials should be flexible enough to form films after coating around non-pareil pellets. Although a series of polymers, such as hydroxypropyl celluloses, Eudragit ${ }^{\circledR}$ polymers, and polyvinyl alcohol, are good film-forming materials, we selected polyvinylpyrrolidone in this study because of its instant dissolution ability and moderate viscosity at a relatively high aqueous concentration. ${ }^{24} \mathrm{After}$ the liquid SNEDDS was dispersed in water, polyvinylpyrrolidone $\mathrm{K} 30$ was added and completely dissolved. Therefore, the coating fluid was in fact a mixture of polyvinylpyrrolidone $\mathrm{K} 30$ aqueous solution and a dispersed nanoemulsion. 


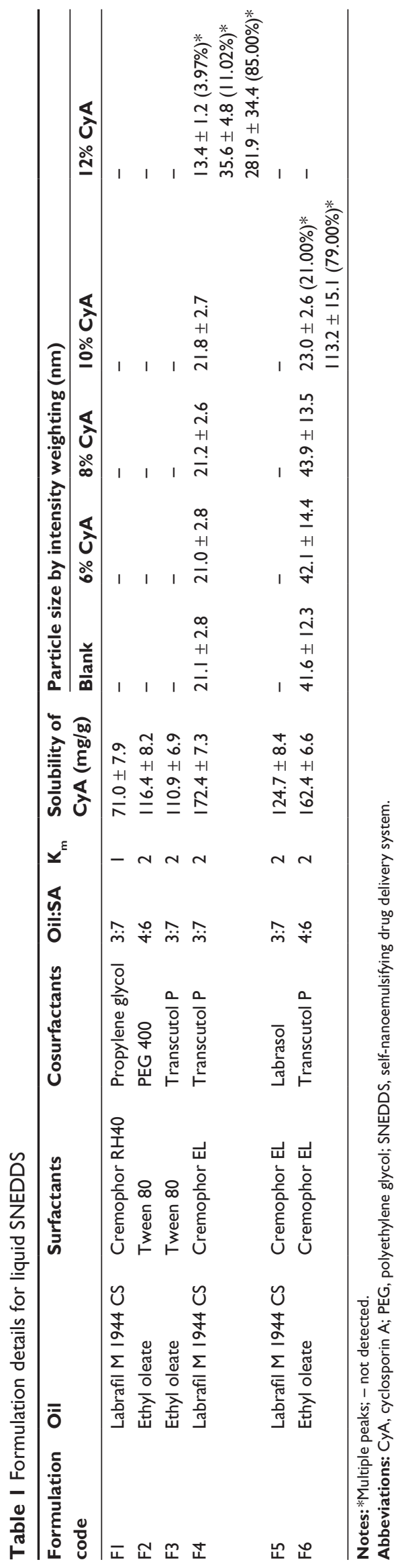

Coating of liquid SNEDDS went smoothly under the coating conditions in this study. Due to the good film-forming properties of polyvinylpyrrolidone $\mathrm{K} 30$ and the relative low viscosity of the bulk liquid, the coating process was made flexible to produce good quality pellets within a wide range of preparative conditions. To identify the capacity of fluidbed coating to hold liquid SNEDDS, we investigated the formulations containing different levels of liquid SNEDDS in the coating layer $(0 \%-40 \%)$. Moreover, we also investigated the formulations containing different levels of cyclosporin A in the liquid SNEDDS $(6 \%-8 \%)$ and the formulations with different CWG (100\%-400\%). Table 2 shows the formulation details of the solid SNEDDS pellets investigated in this study. All batches of products could be obtained with a high yield of over $80 \%$, except for the formulation containing $50 \%$ liquid SNEDDS that produced only aggregates of pellets due to the presence of too much liquid. Figure 2 shows that all batches of the solid SNEDDS pellets were white and spherical, and no trace of SNEDDS "oil" in the outer surface of the pellets could be observed visually. Figure 3 shows the scanning electron microscopic photographs of the solid SNEDDS pellets prepared under different conditions. When the liquid SNEDDS content was over $30 \%$ in the coating layer, the outer surface of the pellets was smooth. This could be attributed to the plasticizing effect of the liquid SNEDDS because oils, surfactants, and cosurfactants in the formulation can work as plasticizers. ${ }^{30}$ However, the surfaces of the final products were not smooth at all when the liquid SNEDDS level was lower than $20 \%$ because of the presence of less "plasticizer". From the cross-sectional view of the pellets, the layer of solid SNEDDS was tightly packed and could be easily distinguished from the non-pareil cores.

However, the presence of non-pareil cores led to an enlarged volume of the dosage form as compared with the pellets prepared by extrusion/spheronization without use of non-pareil cores. One approach to overcome this problem is to increase the thickness of the coating layer. If the pellets were prepared at $100 \%$ CWG, the non-pareil cores would occupy $50 \%$ of the weight of the total formulation. If the CWG were increased to $400 \%$, the non-pareil cores would occupy only $20 \%$ of the weight of the final product. Theoretically, solid SNEDDS pellets can be produced at any CWG as long as the coating is kept. However, a significant increase in CWG leads to significantly increased diameter and bulk weight of the pellets, resulting in a significant change in their aerodynamic conditions. Obvious disorder in the fluidized status could be observed visually from the observing window of the fluid-bed coater. Although a CWG 
Table 2 Formulation details for solid SNEDDS pellets

\begin{tabular}{|c|c|c|c|c|c|c|}
\hline $\begin{array}{l}\text { Formulation } \\
\text { code }\end{array}$ & $\begin{array}{l}\text { Liquid SNEDDS } \\
\text { loading in the } \\
\text { coating layer (\%) }\end{array}$ & $\begin{array}{l}\text { Theoretical } \\
\text { CWG (\%) }\end{array}$ & $\begin{array}{l}\text { CyA loading in } \\
\text { the Liquid } \\
\text { SNEDDS (\%) }\end{array}$ & $\begin{array}{l}\text { Coating gain } \\
\text { of protective } \\
\text { coating with } \\
\text { PVP K30 (\%) }\end{array}$ & Recovery (\%) & Friability (\%) \\
\hline SFO & I & 200 & 1 & I & 79.5 & 0.19 \\
\hline SFI & 20 & 200 & 8 & 1 & 81.7 & 0.31 \\
\hline SF2 & 30 & 200 & 8 & I & 82.6 & 0.29 \\
\hline SF3 & 40 & 200 & 8 & l & 84.8 & 0.15 \\
\hline SF4 & 50 & 200 & 8 & I & - & - \\
\hline SF5 & 40 & 100 & 8 & I & 81.1 & 0.13 \\
\hline SF6 & 40 & 400 & 8 & I & 81.9 & 0.19 \\
\hline SF7 & 40 & 200 & 6 & l & 83.7 & 0.18 \\
\hline SF8 & 40 & 200 & 10 & I & 82.7 & 0.17 \\
\hline SF9 & 40 & 200 & 8 & 5 & 82.9 & 0.17 \\
\hline
\end{tabular}

Note: - not detected; / not applicable; bold figures denote comparison in each column.

Abbreviations: CWG, coating weight gain; CyA, cyclosporin; PVP, polyvinylpyrrolidone; SNEDDS, self-nanoemulsifying drug delivery system.

of over $400 \%$ can possibly be achieved, we only investigated systems with CWGs less than $400 \%$ because previous experience indicated that increasing CWGs to over $400 \%$ would result in significant change, even collapse, of the fluidizing state of the pellets, necessitating adjustment of

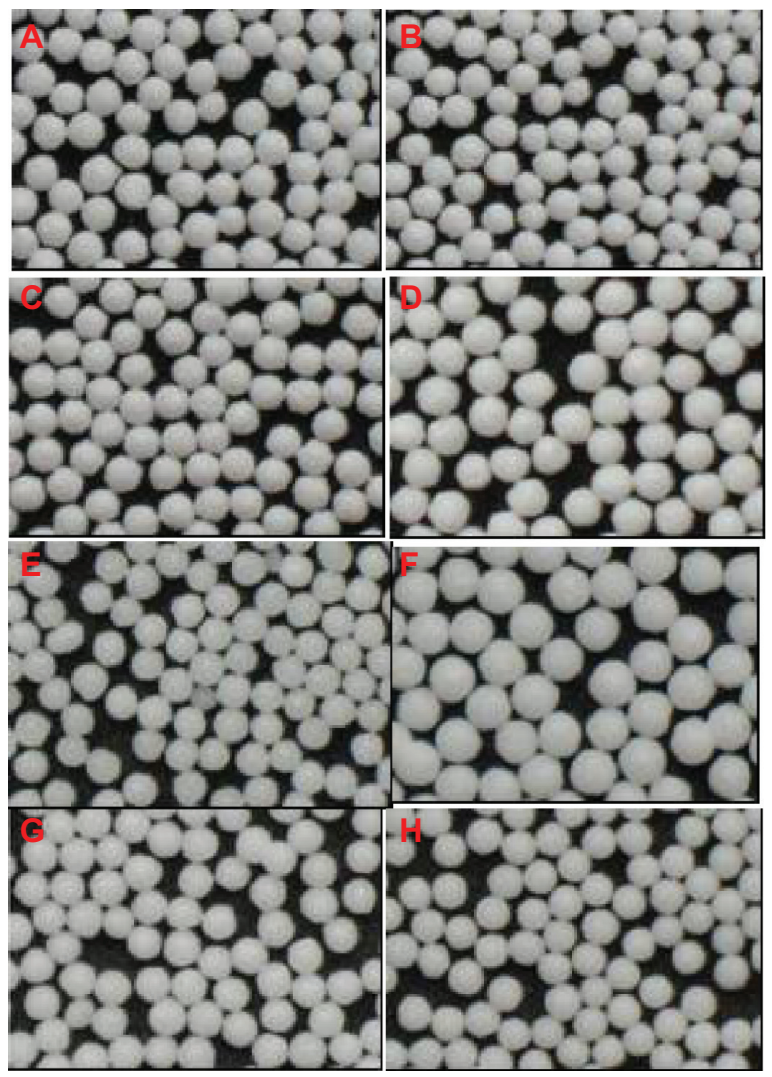

Figure 2 Optical photographs of the solid SNEDDS pellets, where the formulations are defined in Table 2. A-D) SF0-3 (liquid SNEDDS loading 0\%, 20\%, 30\%, 40\%); E, F) SF5, 6 (CWG 100\%, 400\%); G, H) SF7, 8 (cyclosporin A loading 6\%, 10\%). Abbreviations: SNEDDS, self-nanoemulsifying drug delivery system; CWG, coating weight gain. the coating parameters. ${ }^{31}$ In this study, all batches of solid SNEDDS pellets were prepared with good appearance (Figures 2 and 3, and Table 2). In addition to increasing the CWG, the load of liquid SNEDDS in the coating layer can be further increased by screening appropriate adsorbents. However, we focused on the fundamental issues of this technique in this proof-of-concept study, and will leave the optimization work for future investigation.

It should be noted that we avoided using volatile cosurfactants, such as ethanol, in the liquid SNEDDS formulation because any volatile solvents would be removed during the spraying/drying process, leading to significant change in the phase behavior of the liquid SNEDDS.

Although no obvious oozing of "oily" SNEDDS was observed visually on the surface of the pellets, even when the SNEDDS loading was as high as $40 \%$, the solid SNEDDS pellets showed a tendency to stick to each other slightly after being stored at ambient temperature for about 2 weeks. Increasing the liquid SNEDDS content in the coating layer resulted in more severe sticking of the pellets. Therefore, we further coated the solid SNEDDS pellets with a protective layer of polyvinylpyrrolidone K30. The results showed that an outer layer of polyvinylpyrrolidone $\mathrm{K} 30$ at a $5 \%$ CWG level helped to improve the overall appearance and protect the pellets from aggregating, but did not enlarge the bulk volume of the products significantly.

\section{Reconstitution properties of solid SNEDDS pellets}

The solid SNEDDS pellets (SF3 in Table 2) were readily dispersed in deionized water. The resulting aqueous dispersion looked clear (slightly translucent), which was 

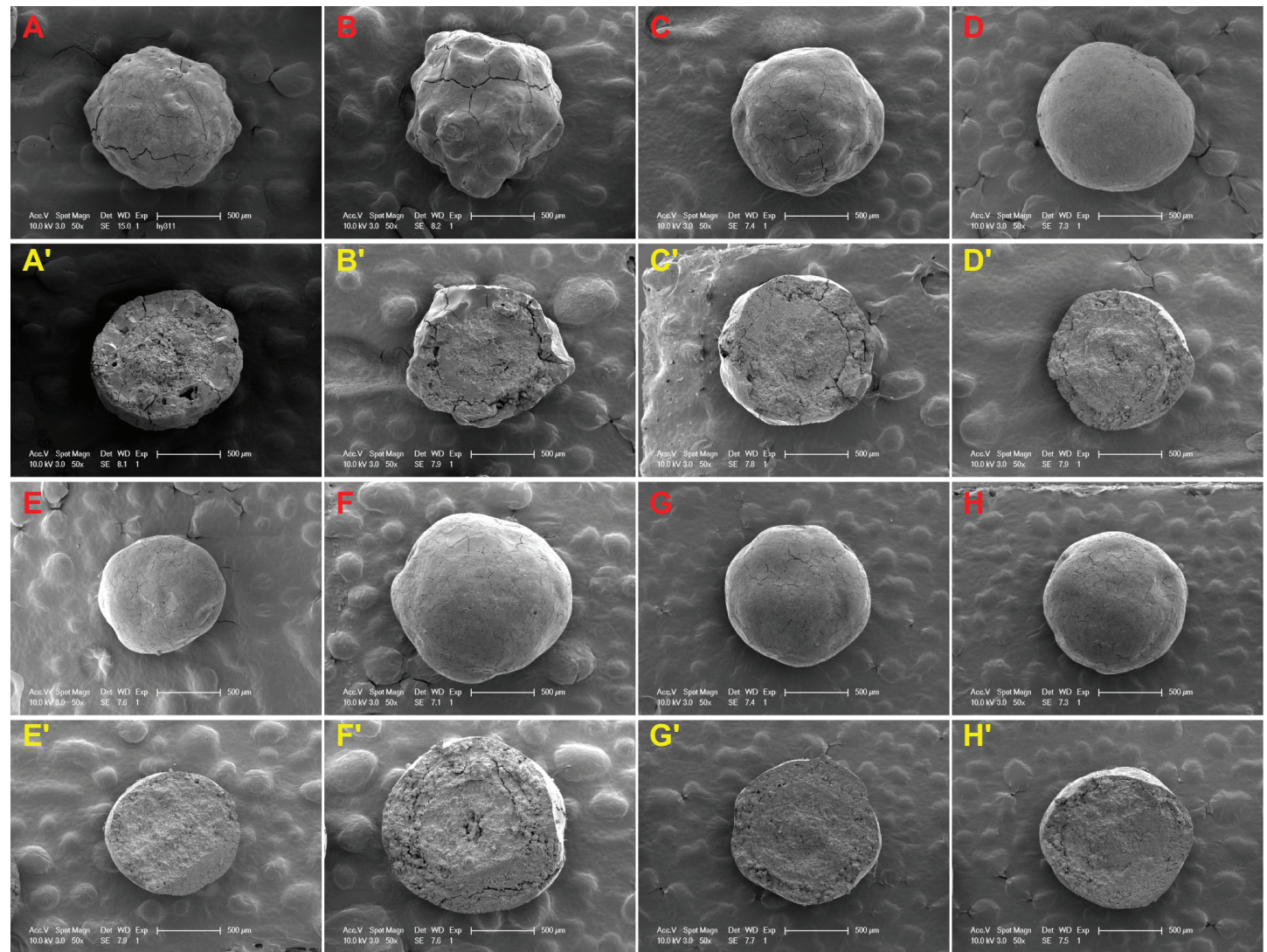

Figure 3 Scanning electron microscopic photographs of the surface and cross-section view of solid SNEDDS pellets, where the formulations are defined in Table 2. Surface: A-D) SFI-3 (liquid SNEDDS loading 0\%, 20\%, 30\%, 40\%); E, F) SF5, 6 (CWG 100\%, 400\%); G, H) SF7, 8 (cyclosporin A loading 6\%, I0\%). Cross-section: A'-D') SFI-3; $\left.\left.\mathbf{E}^{\prime}, \mathbf{F}^{\prime}\right) \mathrm{SF} 5,6 ; \mathbf{G}^{\prime}, \mathbf{H}^{\prime}\right) \mathrm{SF7}, 8$.

Abbreviations: SNEDDS, self-nanoemulsifying drug delivery system; CWG, coating weight gain.

similar to the appearance of the liquid SNEDDS (F4 in Table 1). The particle size of the reconstituted nanoemulsions was $23.7 \pm 2.9 \mathrm{~nm}$, which was not significantly different $(P>0.05)$ from the particle size $(21.2 \pm 2.6 \mathrm{~nm})$ of liquid SNEDDS (F4). The results indicate that solidification of liquid SNEDDS in polyvinylpyrrolidone K30 matrix in the coating layer did not lead to significant variation in the particle size of the nanoemulsion. The self-nanoemulsifying performance was well preserved in the solid SNEDDS pellets.

\section{Powder X-ray diffraction analysis}

A liquid SNEDDS (F4) has the capability to solubilize approximately $16 \%(\mathrm{w} / \mathrm{w})$ cyclosporin $\mathrm{A}$. To guarantee complete solubilization of cyclosporin $\mathrm{A}$ in the formulation after coating, the drug loading was set at less than $10 \%$. However, it is desirable to identify the physical state of cyclosporin A in solid SNEDDS formulations because the presence of solid polyvinylpyrrolidone might alter the solubilizing state of cyclosporin A. Figure 4 shows the powder X-ray diffraction curves of the crystalline cyclosporin A, physical mixture, and solid SNEDDS pellet powder. Figure 4 shows that crystalline cyclosporin A demonstrated typical diffraction peaks ranging from $2.5^{\circ}$ to $45^{\circ}(2 \theta)$, whereas polyvinylpyrrolidone $\mathrm{K} 30$, an amorphous polymer, did not show these typical diffraction peaks. The physical mixture showed diffraction peaks at a position similar to that of crystalline cyclosporin A, with a reduced intensity due to reduced concentration of crystalline cyclosporin A in the mixture. As expected, the solid SNEDDS samples did not show any sign of diffraction, indicating the nonexistence of cyclosporin A precipitate in the final products. We also used differential scanning calorimetry to identify crystalline cyclosporin A in the final products, which nevertheless failed due to the extremely low endotherm of crystalline cyclosporin A. ${ }^{32}$

\section{Redispersibility of solid SNEDDS pellets}

When studying the redispersibility of the solid SNEDDS pellets, we assumed that cyclosporin A was associated with the reconstituted nanoemulsions after redispersing, and then monitored the content of cyclosporin A in the redispersing medium. Theoretically, surface-deposited cyclosporin A can 


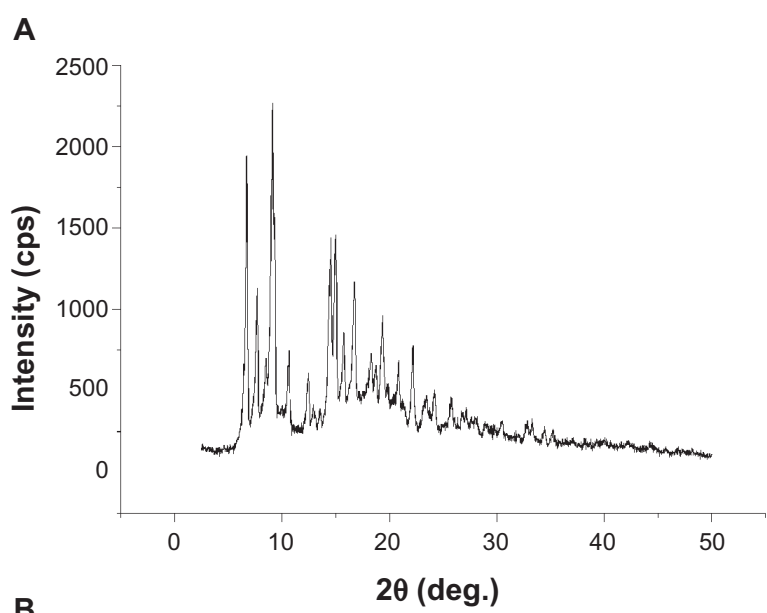

\section{C}
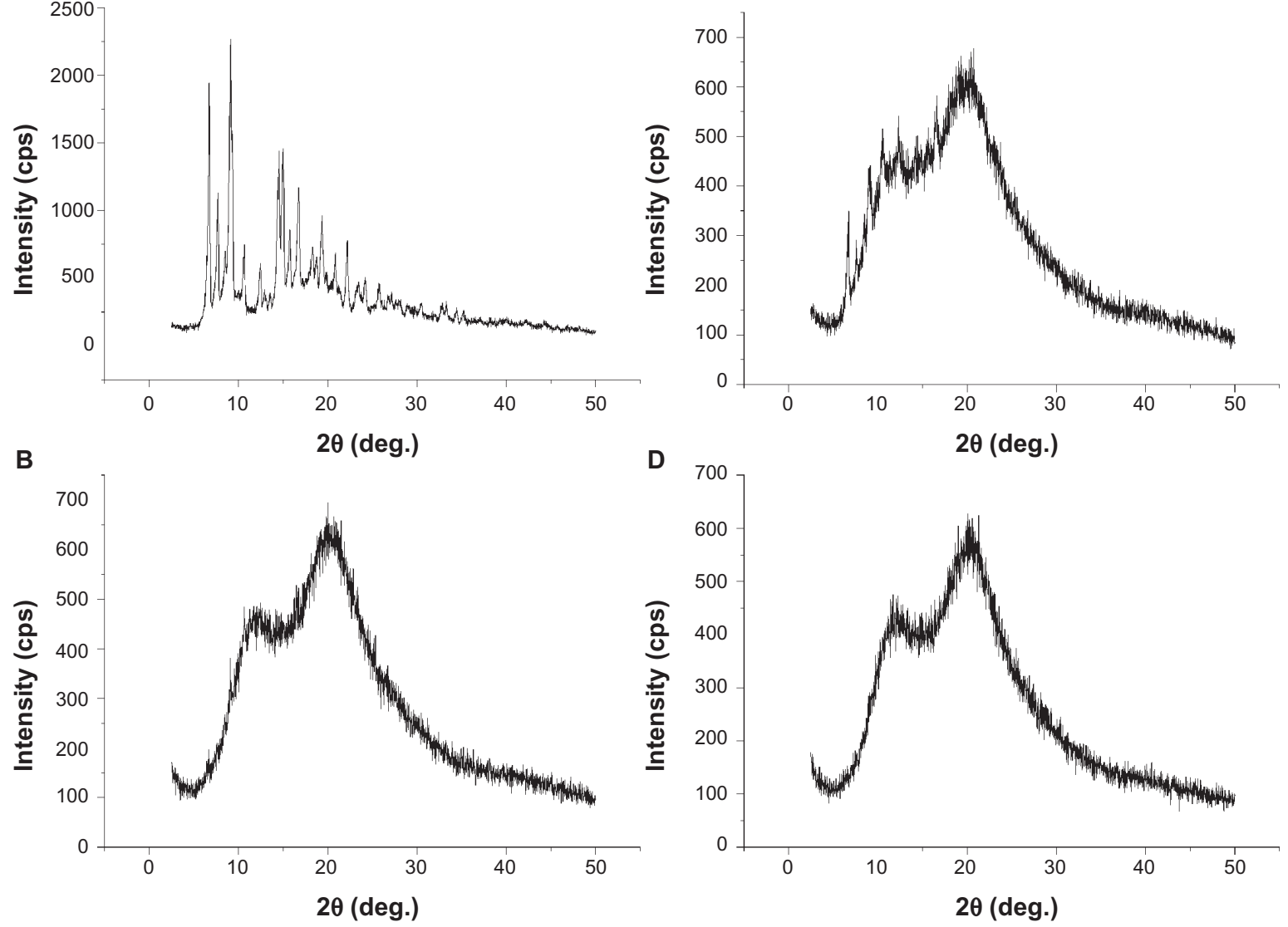

Figure 4 Powder x-ray diffraction patterns of cyclosporin A (A), PVP K30 (B), physical mixture (C) and solid SNEDDS powder (D). Abbreviations: PVP, polyvinylpyrrolidone; SNEDDS, self-nanoemulsifying drug delivery system.

also contribute to the bulk redispersibility profile. However, this was unlikely to have happened in this study because we deliberately used deionized water as the redispersing medium in which the solubility of cyclosporin A was negligible. The rapid redispersion profiles can only be attributed to nanoemulsion-associated cyclosporin A.

Solid SNEDDS pellets should retain the ability of liquid SNEDDS to redisperse quickly into nanoemulsion in aqueous medium. However, the redispersing of SNEDDS from solid pellets may be impeded because the compact coating layer takes time to dissolve. Figure 5 shows the redispersing profiles in water of the solid SNEDDS pellets. Liquid SNEDDS rapidly dispersed into water, achieving near $90 \%$ and $100 \%$ redispersion at 5 and 10 minutes, respectively (Figure 5). All formulations of solid SNEDDS pellets showed a slower redispersing rate compared with those of the liquid SNEDDS. We investigated the effect of some variables on the redispersion rate, including liquid SNEDDS loading in the coating layer, cyclosporin A loading in liquid SNEDDS, $\mathrm{CWG}$, and the outer protective coating. The loading of liquid SNEDDS and total CWG significantly affected the redispersion rate, whereas the loading of cyclosporin A within the investigated range and outer protective coating did not show any significant influence.

The redispersion rate was slowest when the liquid SNEDDS was at the lowest loading level (20\%), which achieved only $70 \%$ redispersion at 10 minutes and complete redispersion at 30 minutes. For formulations containing more liquid SNEDDS (30\% and 40\%), redispersion was faster, achieving approximately $85 \%$ redispersion at 10 minutes, but with a similar redispersion completion time of 30 minutes. The slower redispersion rate can be attributed to the fact that pellets have a smaller dissolution surface and thus a slower dissolution rate for the coating layer, as observed in our previous study of solid dispersion pellets. ${ }^{25}$ However, when the content of liquid SNEDDS in the coating layer was increased to $30 \%-40 \%$, the redispersion rate was increased, which could be interpreted as being due to the readily dispersing nature of the liquid SNEDDS.

Increasing the total CWG to 400 times that of the nonpareil cores significantly reduced the total redispersion rate. As shown in Figure 5B, the redispersion rate was only 
A

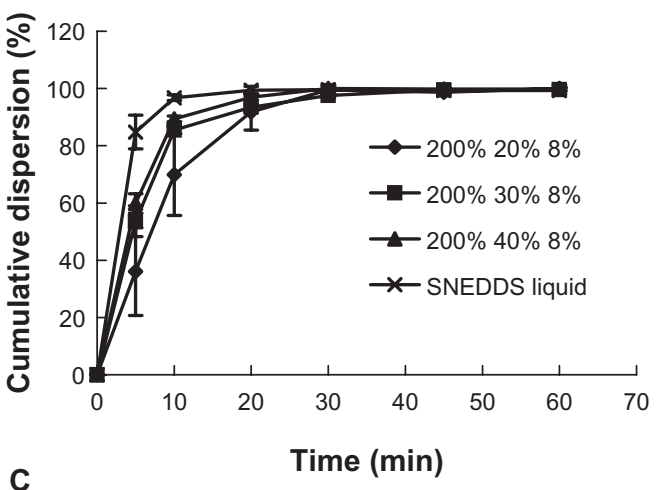

C

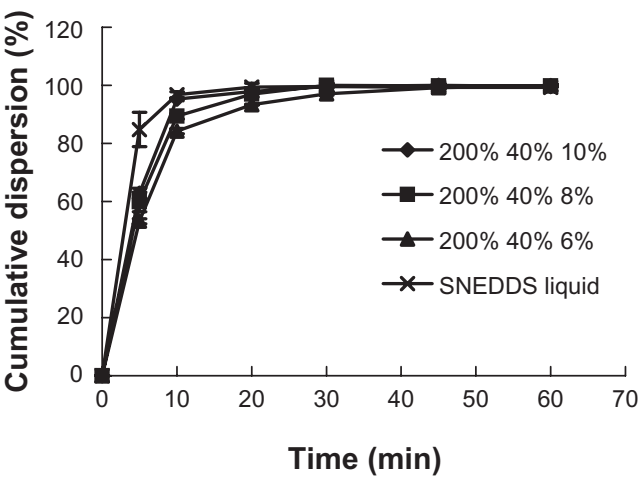

B

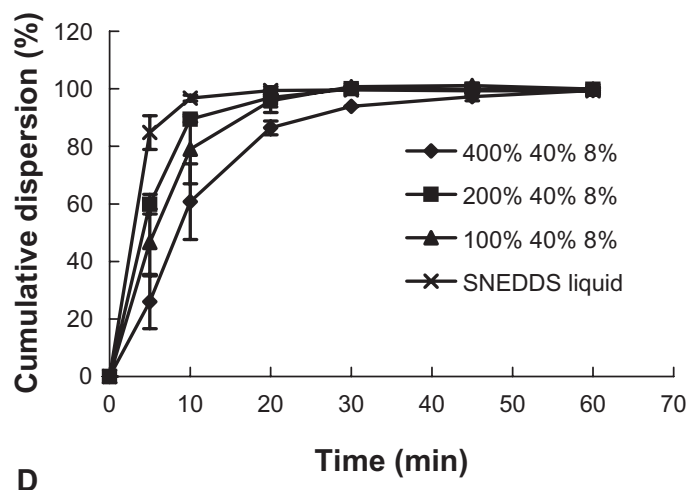

D

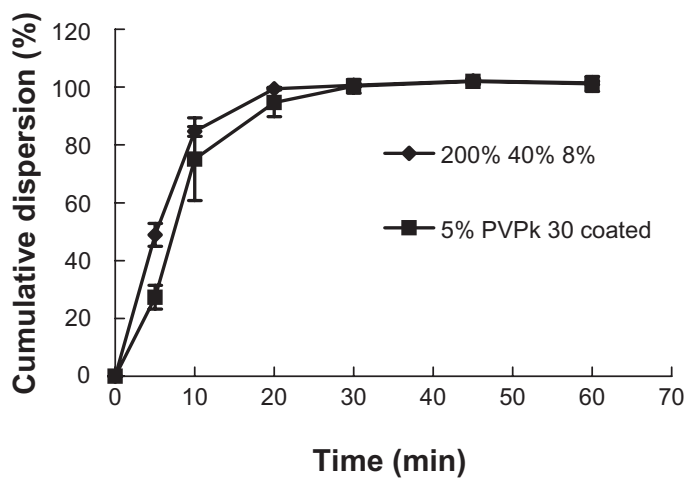

Figure 5 Redispersion profiles of solid SNEDDS pellets, for which the formulations are defined in Table 2. A) SFI-3 (liquid SNEDDS loading 20\%, 30\%, 40\%); B) SF5, 3, 6 (CWG 100\%, 200\%, 400\%); C) SF7, 3, 8 (cyclosporin A loading: 6\%, 8\%, 10\%); D) SF9 (protective PVP 30 coating at 5\%).

Abbreviations: SNEDDS, self-nanoemulsifying drug delivery system; CWG, coating weight gain; PVP, polyvinylpyrrolidone.

$60 \%$ at 10 minutes when CWG was $400 \%$, and it took over 45 minutes to complete the redispersion. This could be explained simply by the increased coating thickness and reduced dissolution surface. It took less than 20 minutes to complete the redispersion when CWG was below 200\%. Although the pellets redispersed somewhat more slowly with $100 \% \mathrm{CWG}$, there was no significant difference between the pellets with CWGs of $100 \%$ and $200 \%$.

Cyclosporin A loading within the range of $6 \%-8 \%$ did not significantly change the redispersion profiles. Although protective coating with 5\% polyvinylpyrrolidone K30 resulted in a slightly slower redispersion rate, there was no significant difference $(P>0.05)$ between protected and unprotected formulations. It is suggested that protective coating with blank polymers like polyvinylpyrrolidone K30 could be a potential approach to improving further the quality of solid SNEDDS pellets.

In general, in vitro characterization and redispersion studies confirmed that the fluid-bed coating could be used as a new technique to prepare solid SNEDDS pellets with good quality and recovery. However, there are still many aspects that need to be clarified. One of the concerns is physical stability upon storage. Special attention should be paid to studying the physical changes in the redispersibility and surface properties (eg, oozing out of the liquid) under stress, and accelerated and long-term testing conditions. Another concern is the effect of solidification and presence of the polymer on self-nanoemulsifying ability and in vivo performance (eg, oral bioavailability). Therefore, we will focus on the effect of solidification on self-microemulsifying properties, stability, and oral bioavailability in the next stage of our research.

\section{Conclusion}

Solid SNEDDS pellets were successfully prepared by a fluid-bed coating technique with high efficiency. Up to $40 \%$ of liquid SNEDDS could be entrapped in the coating layer, with polyvinylpyrrolidone $\mathrm{K} 30$ as the film-forming material. Visual observation and scanning electron microscopic analysis demonstrated good surface properties for the solid SNEDDS pellets. Total coating weight gain up to $400 \%$ could be achieved without interruption of the coating process. A redispersion study in water showed faster release at higher loading levels of liquid SNEDDS, whereas the increase in total coating weight significantly decreased the dispersion rate. This technique has considerable potential for use in the preparation of SNEDDS pellets. 


\section{Acknowledgments}

This study was supported by the National Key Basic Research Program of China (2009CB930300, 2007CB935800), the Shanghai Commission of Science and Technology (0952nm03200), and the Shanghai Municipal Education Commission (10SG05).

\section{Disclosure}

The authors report no conflicts of interest in this work.

\section{References}

1. Lipinski CA. Poor aqueous solubility - an industry wide problem in drug discovery. Am Pharm Rev. 2002;5:82-85.

2. Dressman J, Reppas C. Drug solubility: How to measure it, how to improve it. Adv Drug Deliv Rev. 2007;59:531-532.

3. Pouton CW, Porter CJH. Formulation of lipid-based delivery systems for oral administration: Materials, methods and strategies. Adv Drug Deliv Rev. 2008;60:625-637.

4. Cui J, Yu B, Zhao Y, et al. Enhancement of oral absorption of curcumin by self-microemulsifying drug delivery systems. Int J Pharm. 2009;371: 148-155.

5. Woo JS, Song YK, Hong JY, et al. Reduced food-effect and enhanced bioavailability of a self-microemulsifying formulation of itraconazole in healthy volunteers. Eur J Pharm Sci. 2008;33:159-165.

6. Zvonar A, Berginc K, Kristl A, et al. Microencapsulation of selfmicroemulsifying system: Improving solubility and permeability of furosemide. Int J Pharm. 2010;388:151-158.

7. Nazzal S, Khan MA. Response surface methodology for the optimization of ubiquinone self-emulsified drug delivery system. AAPS Pharm Sci Tech. 2002;3(1):E3.

8. Nazzal S, Smalyukh II, Lavrentovich OD, et al. Preparation and in-vitro characterization of a eutectic based semisolid self nanoemulsified drug delivery system (SNEDDS) of ubiquinone: Mechanism and progress of emulsion formation. Int J Pharm. 2002;235:247-265.

9. Nazzal S, Nutan M, Palamakula A, et al. Optimization of a self-nanoemulsified tablet dosage form of ubiquinone using response surface methodology: Effect of formulation ingredients. Int $J$ Pharm. 2002;240:103-114.

10. Nazzal S, Zaghloul AA, Khan MA. Effect of extragranular microcrystalline cellulose on compaction, surface roughness and in-vitro dissolution of a self-nanoemulsified solid dosage form of ubiquinone. Pharm Technol. 2002;26:86-98.

11. Dixit RP, Nagarsenker MS. Self-nanoemulsifying granules of ezetimibe: Design, optimization and evaluation. Eur J Pharm Sci. 2008;35:183-192.

12. Nazzal S, Khan MA. Controlled release of a self-emulsifying formulation from a tablet dosage form: Stability assessment and optimization of some processing parameters. Int J Pharm. 2006;315:110-121.

13. Ito $\mathrm{Y}$, Kusawake $\mathrm{T}$, Ishida $\mathrm{M}$, et al. Oral solid gentamicin preparation using emulsifier and adsorbent. J Control Release. 2005;105:23-31.

14. Sander C, Holm P. Porous magnesium aluminometasilicate tablets as carrier of a cyclosporine self-emulsifying formulation. AAPS Pharm Sci Tech. 2009;10:1388-1395.

International Journal of Nanomedicine

\section{Publish your work in this journal}

The International Journal of Nanomedicine is an international, peerreviewed journal focusing on the application of nanotechnology in diagnostics, therapeutics, and drug delivery systems throughout the biomedical field. This journal is indexed on PubMed Central, MedLine, CAS, SciSearch ${ }^{\circledR}$, Current Contents ${ }^{\circledR} /$ Clinical Medicine,
15. Boltri L, Coceani N, De Curto D, et al. Enhancement and modification of etoposide release from crosspovidone particles loaded with oilsurfactant blends. Pharm Dev Technol. 1997;2:373-381.

16. Balakrishnan P, Lee BJ, Oh DH, et al. Enhanced oral bioavailability of dexibuprofen by a novel solid self-emulsifying drug delivery system (SEDDS). Eur J Pharm Biopharm. 2009;72:539-545.

17. Yi T, Wang J, Xu H, et al. A new solid-microemulsifying formulation prepared by spray-drying to improve the oral bioavailability of poorly water soluble drugs. Eur J Pharm Biopharm. 2008;70:439-444.

18. Homar M, Šuligoj D, Gašperlin M. Preparation of microcapsules with self-microemulsifing core by a vibrating nozzle method.J Microencapsul. 2007;24:72-81.

19. Wang Z, Sun J, Wang Y, et al. Solid self-emulsifying nitrendipine pellets: Preparation and in vitro/in vivo evaluation. Int J Pharm. 2010; 383:1-6.

20. Abdalla A, Klein S, Mäder K. A new self-emulsifying drug delivery system (SEDDS) for poorly soluble drugs: Characterization, dissolution, in vitro digestion and incorporation into solid pellets. Eur J Pharm Sci. 2008;35:457-464.

21. Abdalla A, Mäder K. Preparation and characterization of a self-emulsifying pellet formulation. Eur J Pharm Biopharm. 2007;66: 220-226.

22. Serratoni M, Newton M, Booth S, et al. Controlled drug release from pellets containing water-insoluble drugs dissolved in a self-emulsifying system. Eur J Pharm Biopharm. 2007;65:94-98.

23. Newton M, Petersson J, Podczeck F, et al. The influence of formulation variables on the properties of pellets containing a self-emulsifying mixture. J Pharm Sci. 2001;90:987-995.

24. Sun N, Wei X, Wu B, et al. Enhanced dissolution of silymarin/ polyvinylpyrrolidone solid dispersion pellets prepared by a one-step fluid-bed coating technique. Powder Technology. 2008;182:72-80.

25. Zhang X, Sun N, Wu B, et al. Physical characterization of lansoprazole/ PVP solid dispersion prepared by fluid-bed coating technique. Powder Technology. 2008;182:480-485.

26. Zhang X, Wu D, Lai J, et al. Piroxicam/2-hydroxypropyl-beta-cyclodextrin inclusion complex prepared by a new fluid-bed coating technique. J Pharm Sci. 2009;98:665-675.

27. Wang Y, Wu W, Que L. Investigation on oil/Tween80/alcohol/water system pseudo-ternary phase diagrams and self-microemulsifying drug delivery system. Chin J Pharm. 2005;36:345-348.

28. Patel AR, Vavia PR. Preparation and in vivo evaluation of SMEDDS (self-microemulsifying drug delivery system) containing fenofibrate. AAPS J. 2007;9:E344-E352.

29. Lai J, Lu Y, Yin Z, et al. Pharmacokinetics and enhanced oral bioavailability in beagle dogs of cyclosporine A encapsulated in glyceryl monooleate/poloxamer 407 cubic nanoparticles. Int J Nanomedicine. 2010;5:13-23.

30. Ide J, Nägele A, Ewald S. Eudragit ${ }^{\circledR}$ Application Guidelines. 10th ed. Parsippany, NJ: Degussa Corporation; 2007

31. Lu Y, Zhang X, Lai J, et al. Physical characterization of meloxicam- $\beta$ cyclodextrin inclusion complex pellets prepared by a fluid-bed coating method. Particuology. 2009;7:1-8.

32. Müller RH, Runge SA, Ravelli V, et al. Cyclosporine-loaded solid lipid nanoparticles $\left(\mathrm{SLN}^{\circledR}\right)$ : Drug-lipid physicochemical interactions and characterization of drug incorporation. Eur J Pharm Biopharm. 2008;68:535-544.

Journal Citation Reports/Science Edition, EMBase, Scopus and the Elsevier Bibliographic databases. The manuscript management system is completely online and includes a very quick and fair peer-review system, which is all easy to use. Visit http://www.dovepress.com/ testimonials.php to read real quotes from published authors. 